\title{
Kvinner har ulike opplevelser av mestring ni år etter brystkreftkirurgi
}

Tidlig diagnose og bedre behandling fører til at flere kvinner overlever brystkreft. Det er viktig med kunnskap om hvordan de mestrer livet etter kreftbehandlingen.

\section{Sigrunn Drageset}

Førsteamanuensis og anestesisykepleier

Institutt for helse og omsorgsvitenskap, Høgskulen på Vestlandet

Torill Christine Lindstrøm

Professor og psykolog

Det psykologiske fakultet, Institutt for samfunnspsykologi og Centre for Early Sapiens

Behaviour, Det humanistiske fakultet, Institutt for arkeologi, historie, kultur- og

religionsvitenskap, Universitetet i Bergen

Sidsel Ellingsen

Førsteamanuensis og anestesisykepleier

VID vitenskapelige høgskole, studiested Haraldsplass, Bergen
Kreft
Kvalitativ studie
Mestring
Overlevelse 
I denne artikkelen har femten kvinner fortalt om hvordan de mestrer livssituasjonen sin ni år etter at de gjennomgikk primær brystkreftkirurgi. Erfaringene kan oppsummeres i tre punkter: livet blir endret, det er viktig å tenke positivt, og de har behov for forståelse og aksept. Helsepersonell bør informere alle kvinner med brystkreft om disse punktene. Støtte og informasjon må tilpasses den enkeltes individuelle behov, mestringsevne og livssituasjon.

«Jeg kan ikke fokusere på det som har vært vanskelig. Jeg må tenke 'Ok, jeg går videre!’ Jeg trenger å fokusere på det positive.» Dette sitatet illustrerer en kvinnes opplevelse ni år etter primæroperasjonen. Hennes erfaring blir diskutert i lys av Antonovskys (1) teori om salutogenese og Lazarus' (2) teori om mestring.

Brystkreft er den hyppigste kreftformen blant kvinner. Tidlig diagnose og bedre behandling gir $\varnothing \mathrm{kt}$ overlevelse (3). I Norge overlever cirka 90 prosent fem år etter diagnosen (4).

Problemer etter behandlingen oppleves ulikt. Noen har få ettervirkninger, mens andre har angst og depresjon $(5,6)$, smerter, tretthet, lymfødem og frykt for tilbakefall $(7,8)$. Informasjon og støtte er viktig for mestring, men må tilpasses ulike faser i forløpet, noe som kan være utfordrende (9-12).

Sosiale roller kan bli forandret fordi kreftbehandlingen påvirker arbeidsengasjement, energinivå og kroppsbilde (13, 14). Imidlertid kan kreftopplevelsen også føre til personlig vekst $(15,16)$. Kunnskap om pasientenes opplevelser av mestring kan gi sykepleiere informasjon om hva som er viktig for å kunne gi individuelt tilpasset oppfølgning.

\section{Mestring innebærer å håndtere utfordringer}

Hensikten med denne artikkelen er å belyse kvinners erfaringer med mestring ni år etter deres primære brystkreftkirurgi. Vi intervjuet femten kvinner individuelt ett og ni år etter operasjonen. Denne artikkelen er en norsk kortversjon av vår engelske artikkel om samme tema. For detaljer om metode og analyse henviser vi til den engelske $\operatorname{artikkelen~(17).~}$

Ifølge Antonovsky (1) innebærer mestring å håndtere utfordringer som oppleves som trusler. Teorien involverer to sentrale begreper: en følelse av sammenheng (SOC) og generelle motstandsressurser (GRR). Disse påvirker hverandre og er avgjørende for mestring. 
En følelse av sammenheng består av tre komponenter: forståelighet, håndterbarhet og meningsfullhet. Generelle motstandsressurser omfatter ulike mestringsressurser, som delvis er knyttet til personens egen mestringskapasitet og delvis til ressurser i miljøet.

Lazarus (2) definerer mestring som kontinuerlig skiftende kognitive og atferdsmessige anstrengelser for å klare spesifikke indre og/eller ytre krav som vurderes som krevende, eller som overstiger ens ressurser.

I vår studie var tre hovedfunn fremtredende: livet blir endret, det er nødvendig å tenke positivt, og forståelse og aksept er viktig.

\section{Livet blir endret}

Kvinnenes livssituasjon ble endret. Endringene ble opplevd både som utfordrende og berikende - uavhengig av hvor alvorlig kreften var. Erfaringene hadde ført til at deres grunnleggende verdier ble tydeligere. Livet ble mer verdsatt; de «små tingene» i livet ga mer glede og fikk større verdi.

Kvinnenes opplevelse av sykdommen fikk konsekvenser for hvordan de prioriterte å bruke tiden sin. Noen ga mer oppmerksomhet til seg selv, mens andre ønsket å gi familien og andre mer tid og oppmerksomhet.

\section{三 «Mange klarte ikke å gå tilbake til sitt tidligere funksjonsnivå.»}

Det ga mening å bruke egne sykdomsopplevelser til å hjelpe andre. En informant sa: «Min kreftopplevelse kan brukes til hjelpe andre med kreft, [...] gjøre kreftopplevelsen mindre farlig.»

A verdsette livet og finne mening er beskrevet i vår tidligere forskning (18). Nå, ni år senere, fant vi at dette var enda mer integrert i kvinnenes levemåte. Ifølge Antonovsky (1) er evnen til å finne mening i vanskelige situasjoner en motiverende faktor som er avgjørende for mestring.

\section{Nederlag å måtte slutte i jobben}

Engasjement i meningsfulle aktiviteter er viktig for å kunne håndtere livsutfordringer for pasienter med brystkreft (14). Også våre funn bekreftet dette. Som Folkman har beskrevet (19), kan meningsfulle opplevelser ha betydning for mestring ved å gi mer innsikt i hva som betyr mest i livet. 
Visse endringer, som tidvis tap av energi, livsglede og selvfølelse, var vanskelig for kvinnene å akseptere. Mange klarte ikke å gå tilbake til sitt tidligere funksjonsnivå: «Jeg har vært glad og hatt arbeidskapasitet. Nå har jeg mistet livsgleden og skapergnisten. Det er både fysisk og psykisk, og jeg orker ikke alltid å være med i fullt tempo.»

Funnene i vår studie viste at det å være $\mathrm{i}$ arbeid var av stor betydning for noen av kvinnene, da det ga identitet og en følelse av normalitet, mestring og å være en aktiv deltaker $i$ samfunnet $(20,21)$ : «Jeg var bekymret for å ikke kunne komme tilbake på jobb, være som alle andre og føle meg frisk.»

Noen jobbet deltid for å få mer energi, mens andre sluttet. $\AA$ måtte slutte i jobben ble opplevd som et nederlag: «Det føltes som et nederlag å måtte slutte å jobbe. Jeg kunne ikke gjøre mitt beste lenger.»

\section{Informasjon kan være en mestringsressurs}

Selvvurdering av arbeidsevne og selvopplevde begrensninger er faktorer som påvirker valget om å være i arbeid $(13,22)$. Det var tøft for kvinnene å forholde seg til mindre energi, tretthet, mindre livsglede og mindre selvtillit. Mange av dem var ikke forberedt på disse endringene, og det var vanskelig å akseptere situasjonen og holde ut.

Mange følte at de ikke hadde fătt nok informasjon fra helsepersonell om mulige langtidseffekter: «Bedre informasjon om hva jeg kunne forvente av plager, kunne gitt meg kontrollen tilbake. Jeg ville ha vært bedre forberedt.»

\section{三 «Jeg vil ikke vite for mye. Jeg vil helst ta dagene slik som de er.»}

Ifølge Lazarus (2) er opplevd kontroll i stressende situasjoner en viktig mestringsressurs. A tilby kvinnene mer individuelt tilpasset informasjon og kunnskap om bivirkninger kan være en måte å styrke deres opplevelse av forståelighet og håndterbarhet på, som beskrevet av Antonovsky (1).

Informasjon og informasjonsmengde må være tilpasset den enkelte: «Jeg vil ikke vite for mye. Jeg vil helst ta dagene slik som de er.» Ifølge Antonovsky (1) er forståelighet en persons evne til å forstå hva som skjer. Personer med en sterk SOC kan se på informasjon som en mulig mestringsressurs, men bare når informasjonen er forståelig og gir mening. 


\section{Det er nødvendig å tenke positivt}

Positiv tenkning var viktig for kvinnene. Det var en nødvendig mestringsstrategi for å holde negative tanker om kreft på avstand. En av dem sa:

«Grunntanken må være at du ikke skal være negativ. Det tror jeg er det viktigste. Du må ha et eller annet å tro på, at dette blir bra, prøve å ha en positiv grunnholdning. Man kan bli syk av å være negativ. Det sprer seg i alt, hvordan du er, hva du gjør, hvordan du tenker i jobben og i det sosiale liv.»

Hvordan kvinnene holdt det negative på avstand, varierte. Noen av dem engasjerte seg i aktiviteter som trening, lyttet til musikk eller deltok i kulturelle begivenheter (18). Det siste kan tolkes som uttrykk for strategier som distanse, normalisering og kognitiv unngåelse $(5,18,23)$.

\section{Håp og indre styrke er viktige ressurser}

Betydningen av å tenke positivt og unngå selvmedlidenhet ble også vektlagt når brystkreftoverleverne oppmuntret og ga råd til andre:

«Det er rådet jeg kan gi folk som blir syke; det er viktig å glemme seg selv litt. Ikke fokusere for mye på seg selv og hva man går gjennom, slik som selvmedlidenhet og det å tenke at livet er urettferdig, og at 'hvorfor skal jeg få det?' Slike tanker kommer, men prøv å holde dem borte. Fors $\varnothing \mathrm{k}$ å ha en positiv holdning. Jeg har sagt til meg selv at jeg er veldig heldig. Det er mange andre som har verre skjebner enn meg. Prøv å føle mer glede! Ikke fokuser på det negative!»

Håp og indre styrke var viktige ressurser for å kunne tenke positivt. En kvinne sa: «Jeg håper at kreften min er fjernet. Håpet holder meg oppe, jeg tror på den indre styrken og er overbevist om at jeg har den. Jeg har aldri tenkt på meg selv som et offer. Legene kan gjøre noe for meg, men resten av ‘jobben’ er min. Livet har mer å tilby. Jeg må komme meg gjennom det og gå videre!»

\section{$\equiv$ ¿Å se fremover og håndtere situasjonen steg for steg var viktig for å holde det negative på avstand.»}

Ifølge Folkman (24) er håp en viktig mestringsressurs for å håndtere usikkerhet og endret virkelighet, noe som også blir vektlagt i forskning $(9,25,26)$. A se fremover og håndtere situasjonen steg for steg var viktig for å holde det negative på avstand. 
Kvinnene ga uttrykk for at de prøvde å unngå å tenke på kreft, og heller fokuserte på overlevelse, selv om de fremdeles følte seg usikre og fryktet tilbakefall. Dette gjenspeiler en mestringsstrategi for å oppleve kontroll og redusere frykt og angst $(18,23,27)$.

\section{Påtrengende tanker er normalt}

Imidlertid ble frykten for tilbakefall aktivert ved rutinekontroller. En kvinne sa: «Nylig, ved rutinekontrollen, begynte jeg å gråte. Jeg tenkte på hva som hadde skjedd der første gangen.» Det var også vanskelig for kvinnene å kjenne andre som hadde fått tilbakefall.

Påtrengende tanker, gjenopplevelse av kreftrelaterte hendelser og unngåelse av alt som handler om kreft, er normalt blant kreftoverlevere, spesielt de første årene etter diagnosen (8). Vi fant at frykt for tilbakefall var gjeldende ni år etter operasjonen, selv om kvinnene fors $\varnothing$ kte å unngå denne frykten. Gjenopplevelser ble utløst av rutinekontrollene.

Ikke alle kvinnene godtok at kroppen var endret.

Rekonstruksjon av bryst var noe alle vurderte, men ikke alle utførte: «Jeg er veldig glad for at jeg bestemte meg for brystrekonstruksjon. Mannen min også. Da jeg bare hadde ett bryst, ble jeg minnet om kreft hele tiden.» En annen sa: «Jeg ville ikke ha brystrekonstruksjon. Jeg er ikke opptatt av forfengelighet.»

$\AA$ akseptere både positive og negative følelser relatert til konsekvensene av kreftsykdom og behandling er en viktig følelsesregulerende prosess (19). Betydningen av å akseptere diagnosen hos brystkreftoverlevende er rapportert av Blinder og medarbeidere (20).

Likevel var konsekvensene av å bli behandlet for brystkreft vanskelig å godta for kvinnene. Imidlertid medførte brystrekonstruksjon at noen aksepterte situasjonen, slik at de ikke hele tiden ble påminnet om kreften. Det ble opplevd som en viktig mestringsfaktor.

\section{Forståelse og aksept er viktig}


Forståelse og aksept for den endrede livssituasjonen var viktig for alle kvinnene: «Folk vet ikke hva du har vært igjennom når de sier: 'Nå er du jo ferdig med behandlingen, så nå er jo alt bra!' For det er ikke alt som er bra! Det har jo med følelser å gjøre òg. Noen ser på meg som helt frisk. Jeg er ikke frisk. Noen ganger må jeg minne folk på at jeg ikke er hjemme fordi jeg har ferie.»

Å motta forståelse var ikke alltid enkelt, da det innebar å være åpen overfor familie, venner og kolleger. En av kvinnene sa: «Hvis jeg er mer åpen om plagene mine [...] kanskje andre vil forstå meg bedre?»

Forståelse og støtte fra partneren var spesielt viktig. De kvinnene som var i jobb, fikk god forståelse av sine kolleger de første årene etter operasjonen, men opplevde at det endret seg ettersom tiden gikk: «Jeg hadde disse 'superflinke' kollegene som ikke forsto. Når du er syk, må andre gjøre jobben din.»

\section{三 «Åpen kommunikasjon om situasjonen i kvinnenes nettverk ga aksept og styrket deres relasjonelle bånd.»}

De positive effektene av sosial støtte er godt dokumentert (5, 11, 14). Våre funn viste at kvinnenes behov for sosial st $\varnothing$ tte var viktig, men at den måtte bli mer tilpasset deres nåværende livssituasjon.

Å få forståelse og aksept var viktig for alle, og de ble opprørte når venner og familie ignorerte alvoret i plagene deres etter behandlingen. Åpen kommunikasjon om situasjonen i kvinnenes nettverk ga aksept og styrket deres relasjonelle bånd.

\section{De næreste er viktige støttespillere}

Ifølge Antonovsky (1) beskrives håndterbarhet som i hvilken grad man opplever å ha de nødvendige mestringsressursene for å håndtere en utfordrende situasjon. Som i tidligere studier (14) fant vi at partneren var den aller viktigste støtten. 
Nære venner og familiemedlemmer var de viktigste st $\varnothing t t e s p i l l e r n e$ for brystkreftoverleverne. Over tid ble st $\varnothing t t e n$ som ble tilbudt, opplevd annerledes, avhengig av om deres endrede livssituasjon ble forstått eller ikke. En kvinne sa: «Jeg har venner som nesten kan 'overdo it' i forhold til å gi hjelp. De gjør for mye ut av det. Jeg liker det ikke. Jeg er et selvstendig menneske.»

De som tidligere hadde opplevd manglende støtte i krevende situasjoner, avviste nå tilbud om hjelp. En av kvinnene sa: «Mannen min hadde kreft i flere år før han døde, og det er ganske tøft når du har to barn å ta vare på. Ingen brydde seg da. Så jeg er ikke interessert i å involvere dem i min situasjon nå.»

\section{Bevissthet om behovet for støtte}

Andre kvinner måtte gi støtte istedenfor å motta det. En informant sa: «Jeg har fått begrenset st $\varnothing t t e$ fra familien min i løpet av disse årene. Min familie krever hjelp og st $\varnothing t t e$ hele tiden. Jeg må hjelpe dem. Jeg har aldri hatt fritid. Jeg føler meg trett.»

Imidlertid kunne støtten også oppleves som overbeskyttende og «frata» enkelte kvinner selvbestemmelse og uavhengighet, mens andre manglet støtte når de trengte det som mest.

Det var viktig for kvinnene å være klar over behovet for støtte og være selektiv når det gjaldt hvem de ønsket å tilbringe tiden sin med: «Jeg er mer utvelgende. Det kan være venner og kolleger. Jeg har funnet ut at nå er det jeg som velger, og jeg velger også vekk noen. Du lever ikke for alltid. Jeg vil fylle tiden min med hyggelige mennesker som virkelig forstår min situasjon.»

$\AA$ være omgitt av positive mennesker var også viktig: «Nå er jeg heldigvis omgitt av relativt positive mennesker på jobb. Jeg har noen i familien min som ikke er spesielt positive, men det plager meg ikke. Jeg foretrekker å omgås dem som er positive. De er rett og slett lettere å være i lag med.»

\section{Ikke alle fastleger kan nok om brystkreft}

Selv om støtte fra kolleger ble verdsatt, fant vi også at manglende forståelse fra overordnede og kolleger kunne skape en følelse av å ikke mestre jobben og et ønske om å slutte. Ved at kvinnene deltok i et støttende miljø på jobben, kunne deres mestringsfølelse og følelse av egenverd styrkes $(13,20)$. 
St $\varnothing$ tte fra helsepersonell var viktig: «Min fastlege har st $\varnothing t t e t$ meg mye. Hun følger meg opp angående jobb og sykmelding.» Men det kunne også være motsatt: «Jeg ser sjelden min fastlege. Jeg har en legesjekk en gang i året. Ikke alle leger vet så mye om brystkreft.»

På linje med tidligere studier var fastlegen en viktig mestringsressurs for noen av kvinnene (28). Imidlertid uttrykte enkelte at fastlegen ikke hadde nok kunnskap om deres krefttype. Manglende kunnskap er rapportert som en barriere for god omsorg ved oppfølgning (28).

\section{Konklusjon}

Kreftopplevelsen forandret livet til kvinnene, også etter lang tid. Hvordan den enkelte mestret sin endrede livssituasjon, varierte. De foretrakk færre, men utvalgte st $\varnothing t t e s p i l l e r e . ~ D e t$ at andre forsto og aksepterte kvinnenes endrede livssituasjon, var avgjørende for at de aksepterte den selv.

\section{Implikasjoner for praksis}

Helsepersonell bør forberede kvinner på en endret livssituasjon etter behandling for brystkreft. Sosial st $\varnothing$ tte og informasjon som tilbys, må tilpasses den enkeltes individuelle behov, mestringsevne og livssituasjon, og de bør oppfordres til å være åpne om situasjonen.

På den måten kan kvinner få mer forståelse og aksept for endringene. Helsepersonell bør også formidle håp og optimisme ved å gi konkrete råd om hvordan de kan få en bedre hverdag.

Forfatterne takker alle kvinnene som deltok $i$ studiene, og som så generøst delte sine erfaringer med oss. Vi takker også Haukeland universitetssjukehus, Bryst- og endokrinkirurgi poliklinikk, for verdifull støtte.

\section{Referanser}

1. Antonovsky A. Unraveling the mystery of health: how people manage stress and stay well. San Francisco: JosseyBass; 1987.

2. Lazarus RS. Stress and emotion: a new synthesis. New York: Springer; 1999. 
3. Verdens helseorganisasjon. Breast cancer: burden and control. WHO; 2016. Tilgjengelig fra:

http://www.who.int/cancer/detection/breastcancer/en/index1. html (nedlastet 07.01.2020).

4. Kreftregisteret. Cancer in Norway. Oslo; 2016.

Tilgjengelig fra:

https://www.kreftregisteret.no/Generelt/Rapporter/Cancer-in-

Norway/cancer-in-norway-2016/ (nedlastet 07.01.2020).

5. Brandao T, Schulz MS, Matos PM. Psychological adjustment after breast cancer: a systematic review of longitudinal studies. Psycho-Oncology. 2016;26(7). DOI:

10.1002/pon.4230

6. Antoni MH, Jacobs JM, Bouchard LC, Lechner SC, Jutagir DR, Gudenkauf LM, et al. Post-surgical depressive symptoms and long-term survival in non-metastatic breast cancer patients at 11-year follow-up. General Hospital Psychiatry. 2017;44:16-21. DOI:

10.1016/j.genhosppsych.2016.10.002

7. Fu MR, Kang Y. Psychosocial impact of living with cancer-related lymphedema. Semin Oncol Nurs. 2013;29(1):50-60. DOI: 10.1016/j.soncn.2012.11.007

8. Stanton AL, Rowland JH, Ganz PA. Life after diagnosis and treatment of cancer in adulthood: contributions from psychosocial oncology research. Am Psychol. 2015;70(2):15974. DOI: $\underline{10.1037 / \mathrm{aOO} 37875}$

9. Prip A, Moller KA, Nielsen DL, Jarden M, Olsen MH, Danielsen AK. The patient-healthcare professional relationship and communication in the oncology outpatient setting: a systematic review. Cancer Nurs. 2018;41(5):E11-E22. DOI: $10.1097 /$ NCC.0000000000000533

10. Lewis S, Yee J, Kilbreath S, Willis K. A qualitative study of women's experiences of healthcare, treatment and support for metastatic breast cancer. Breast. 2015;24(3):242-7. DOI: $\underline{10.1016 / \mathrm{j} . \text { breast.2015.02.025 }}$

11. Chou AF, Stewart SL, Wild RC, Bloom JR. Social support and survival in young women with breast carcinoma. PsychoOncology. 2012 februar;21(2):125-33. DOI: 10.1002/pon.1863 
12. Drageset S, Lindstrom TC, Giske T, Underlid K.

Women's experiences of social support during the first year following primary breast cancer surgery. Scand J Caring Sci. 2016;30(2):340-8. DOI: $10.1111 /$ scs.12250

13. Sun Y, Shigaki CL, Armer JM. Return to work among breast cancer survivors: A literature review. Support Care Cancer. 2017 mars;25(3):709-18. DOI: 10.1007/so0520-0163446-1

14. Jakobsen K, Magnus E, Lundgren S, Reidunsdatter RJ. Everyday life in breast cancer survivors experiencing challenges: A qualitative study. Scand J Occup Ther. 2018;25(4):298-307. DOI: 10.1080/11038128.2017.1335777

15. Danhauer SC, Case LD, Tedeschi R, Russell G, Vishnevsky T, Triplett K, et al. Predictors of posttraumatic growth in women with breast cancer. Psycho-Oncology. 2013;22 (12):2676-83. DOI: 10.1002/pon.3298

16. Fang Y. Empirical Analysis of post-traumatic growth status and influencing factors for breast cancer inpatients base on posttraumatic growth inventory. Boletín Técnico. 2017;55(7):716-24.

17. Drageset S, Lindstrom TC, Ellingsen S. «I have both lost and gained.» Norwegian survivors' experiences of coping 9 years after primary breast cancer surgery. Cancer Nurs. 2020;43(1):E3O-E37. DOI: 10.1097/NCC.0000000000000656

18. Drageset S, Lindstrom TC, Underlid K. «I just have to move on»: Women's coping experiences and reflections following their first year after primary breast cancer surgery. Eur J Oncol Nurs. 2016;21:205-11. DOI:

$\underline{10.1016 / \text { j.ejon.2015.10.005 }}$

19. Folkman S. The case for positive emotions in the stress process. Anxiety Stress Coping. 2008;21(1):3-14. DOI: $\underline{10.1080 / 10615800701740457}$

20. Blinder VS, Murphy MM, Vahdat LT, Gold HT, de MeloMartin I, Hayes MK, et al. Employment after a breast cancer diagnosis: a qualitative study of ethnically diverse urban women. J Community Health. 2012;37(4):763-72. 
21. Wells M, Williams B, Firnigl D, Lang H, Coyle J, Kroll T, et al. Supporting 'work-related goals' rather than 'return to work' after cancer? A systematic review and meta-synthesis of 25 qualitative studies. Psycho-Oncology. 2013;22(6):1208-19.

DOI: 10.1002/pon.3148

22. Von Ah D, Storey S, Crouch A, Johns SA, Dodson J, Dutkevitch S. Relationship of self-reported attentional fatigue to perceived work ability in breast cancer survivors. Cancer Nurs. 2017;40(6):464-70. DOI:

10.1097/ncc.0000000000000444

23. Drageset S, Lindstrom TC, Underlid K. Coping with breast cancer: between diagnosis and surgery. J Adv Nurs. 2010;66(1):149-58. DOI: $10.1111 / \mathrm{j} \cdot 1365-2648.2009 .05210 . x$

24. Folkman S. Stress, coping, and hope. Psycho-Oncology. 2010;19(9):901-8. DOI: 10.1002/pon.1836

25. Nierop-van Baalen C, Grypdonck M, van Hecke A, Verhaeghe S. Hope dies last ... A qualitative study into the meaning of hope for people with cancer in the palliative phase. Eur J Cancer Care. 2016;25(4):570-9. DOI:

$\underline{10.1111 / \text { ecc. } 12500}$

26. Rustoen T, Cooper BA, Miaskowski C. The importance of hope as a mediator of psychological distress and life satisfaction in a community sample of cancer patients. Cancer Nurs. 2010;33(4):258-67. DOI:

$\underline{10.1097 / \text { NCC.obo13e3181d6fb61 }}$

27. Mehrabi E, Hajian S, Simbar M, Hoshyari M, Zayeri F. Coping response following a diagnosis of breast cancer: A systematic review. Electron Physician. 2015;7(8):1575-83. DOI: $\underline{10.19082 / 1575}$

28. Meiklejohn JA, Mimery A, Martin JH, Bailie R, Garvey G, Walpole ET, et al. The role of the GP in follow-up cancer care: a systematic literature review. J Cancer Surviv. 2016;10(6):990-1011. DOI: 10.1007/s11764-016-0545-4 